\title{
Mobilização de um coletivo de catadores: prática em Clínica Psicodinâmica da Cooperação
}

\author{
Liliam Deisy Ghizoni ${ }^{1}$ \\ Universidade Federal do Tocantis (Palmas, TO) \\ Ana Magnólia Mendes² \\ Universidade de Brasília (Brasília, DF)
}

\begin{abstract}
Neste artigo, apresentam-se os resultados de uma prática em Clínica Psicodinâmica da Cooperação com trabalhadores vinculados a uma associação de catadores. Parte-se do referencial da Psicodinâmica do Trabalho, que se caracteriza como uma escuta clínica para sujeitos que resistem às diversas formas de sofrimento no trabalho impostas por sua organização, além de ser promotora de saúde por meio da mobilização subjetiva do coletivo de trabalhadores. Objetivase aqui descrever esta mobilização por meio de uma pesquisa qualitativa de caráter descritivo. Foram 12 sessões com a participação de 16 catadores pouco escolarizados, de idade entre 39 e 78 anos. Houve a transição de uma gestão individual para uma gestão coletiva, ainda em processo de estruturação e aprendizado. A mobilização subjetiva que aconteceu no percurso da Clínica continuou reverberando no coletivo de catadores, o qual, após a constituição do coletivo gestor, promoveu mudanças na organização laboral e apropriou-se do real do trabalho e da gestão coletiva da associação; estes foram os principais efeitos desta prática. Destarte, a maior demonstração deste estudo é a importância da Clínica como potencial político de organização coletiva.
\end{abstract}

Palavras-chave: Psicodinâmica do Trabalho, Mobilização subjetiva, Cooperação, Espaço de discussão, Inteligência prática, Catadores de materiais recicláveis.

Mobilization of a collective of waste pickers: practice in Psychodynamic Cooperation Clinic

In this article, we present the results of a practice in Psychodynamic Cooperation Clinic with workers linked to a waste pickers association from the point of view of Work Psychodynamics, which is characterized as a clinic listening to subjects who withstand the various types of suffering at work imposed by its organization and promotes health by means of a subjective mobilization of the collective of workers. This study aims to describe this mobilization through a qualitative and descriptive research. There were 12 interview sessions including the participation of 16 waste pickers, aged between 39 to 78 years with little schooling. There was the transition from single management to collective management, which is still in structuring and learning process. The subjective mobilization that took place during the practice of the Clinic continued reverberating in the collective of collectors, which, after the formation of the collective management, promoted changes in work organization and took possession of the real of the work and the collective management of the association; these were the main effects of this practice. Thus, the greatest demonstration of this study is the importance of the Clinic as political potential of collective organization.

Keywords: Work Psychodynamics, Subjective mobilization, Cooperation, Space for discussion, Practical intelligence, Pickers of recyclable material.

\section{Introdução}

$\mathrm{E}$ ste estudo apresenta os resultados de uma prática em Clínica Psicodinâmica da Cooperação com trabalhadores vinculados à Associação de Catadores e Catadoras de Materiais Recicláveis da Região Centro Norte de Palmas, Tocantins (ASCAMPA), uma população excluída dos meios de produção, mas que tenta se manter viva através da união de esforços no ofício da catação.

A ocupação de catadores de materiais recicláveis existe no Brasil, de maneira informal, há mais de cinquenta anos, porém, desde 2002, integra o Código Brasileiro de Ocupações do Ministério do Trabalho e Emprego, com a denominação da família ocupacional dos catadores de

1 Universidade Federal do Tocantins - UFT. Colegiado de Administração. Programa de Pós Graduação em Gestão de Políticas Públicas.

2 Universidade de Brasília - UnB. Instituto de Psicologia, Programa de Pós Graduação em Psicologia Social, do Trabalho e das Organizações. 
materiais recicláveis (Sousa \& Mendes, 2006). Estima-se que o número de catadores no Brasil gire em torno de 400 a 600 mil trabalhadores (Freitas \& Fonseca, 2012).

Vale destacar que material reciclável e lixo são muitas vezes confundidos, assim, é relevante explicitar que lixo - considerado por muitas pessoas como aquilo que não presta - é constituído por uma parcela de $40 \%$ de materiais recicláveis. Dessa forma, nem tudo que vai para o lixo "não presta" de fato. Material reciclável ou reutilizável é um resíduo sólido que constitui interesse de transformação que tem mercado ou operação que viabiliza sua modificação (Gonçalves, 2003). É nesta transmutação do lixo em mercadoria que atua o personagem central deste estudo: o catador (também separador, prensador, vendedor, articulador, conscientizador) de materiais recicláveis. Porém, como afirmam Santos e Silva (2009), historicamente, o lixo foi tratado pejorativamente como algo a ser expurgado de dentro das casas, comércios e indústrias, pois um "alguém" passaria para retirá-lo. Assim, ao se "livrar" do lixo, reforça-se a sensação de repulsa nas pessoas, afirmam os autores. Fatos como estes só contribuem para a vulnerabilidade em que estes trabalhadores se encontram.

Embora haja esta diferença entre lixo e materiais recicláveis, catadores de materiais recicláveis ainda são confundidos com catadores de lixo, sobretudo pelos meios de comunicação. Assim, constitui-se uma bandeira dos catadores afirmar sua identidade como catadores de materiais que podem ser transformados, reciclados, reaproveitados, com um importante papel de agente ambiental na sociedade, embora pouco valorizado pelo Poder Público (Feitosa, 2011).

Ressalta-se que em 2 de agosto de 2010, após mais de vinte anos em tramitação, entrou em vigor a Lei $n^{\circ}$ 12.305, que institui a Política Nacional de Resíduos Sólidos, cria o Comitê Interministerial da Política Nacional de Resíduos Sólidos e o Comitê Orientador para a Implantação dos Sistemas de Logística Reversa (Brasil, 2010; Feitosa, 2011). Esta Lei estabelece prazos para que estados e municípios brasileiros elaborem seus planos de gestão de resíduos sólidos com a colaboração dos catadores. Gonçalves (2003) chama a atenção para a forma como a coleta seletiva vem sendo implantada nos municípios - observa-se que em muitos casos os catadores são mantidos à margem deste sistema, que não contempla, assim, o aspecto social da tríade ambiental, social e econômica que a atividade requer.

Os dados de 2008 confirmam o panorama acima, demonstrando haver 994 municípios brasileiros (apenas 18\%) com coleta seletiva implantada: 66\% dos quais com parceria firmada com catadores de materiais recicláveis (Besen, 2011). Há ainda um agravante a este dado: a forma precária da parceria, pois, apesar de os catadores fazerem um trabalho de limpeza urbana e pública, não são remunerados por este serviço (Ghizoni, 2013).

Em Palmas, capital do Tocantins, onde a pesquisa de campo foi realizada, não há uma política pública voltada para os catadores. Destaca-se que esta não é uma realidade única: em Fortaleza (CE), as ações de coleta seletiva acontecem de forma isolada e sem a participação efetiva da prefeitura, o que só potencializa as práticas assistencialistas e mantenedoras dos catadores nas ruas, fazendo um serviço público sem remuneração (Feitosa, 2011).

Há que se caminhar muito para que a Política Nacional de Resíduos Sólidos, que tem por objetivo promover a inclusão social dos catadores mediante o fomento às cooperativas e associações formadas por pessoas de baixa renda, avance pelo país adentro.

A ASCAMPA foi criada oficialmente em 25 de setembro de 2005 (Ata da Assembleia Geral de fundação da ASCAMPA, 2005). Iniciou-se com 16 catadores e chegou a ter 69 catadores vinculados (Ghizoni \& Cançado, 2011). Na época da realização deste estudo, primeiro semestre de 2012, contava com 34 catadores cadastrados. Neste contexto histórico, a gestão da associação era feita por um catador fundador, com a diretoria composta de quatro catadores: presidente, vice-presidente, secretário e tesoureiro, que pouco ou nada se envolvia nas deliberações desta gestão. Observava-se a centralização do poder decisório e uma baixa participação dos associados.

Neste cenário e com a demanda dirigida ao Núcleo de Economia Solidária da Universidade Federal do Tocantins (NESol/UFT) para a constituição de uma cooperativa, deu-se início este 
estudo. O Núcleo não podia atender este pedido deles, mas poderia abrir um espaço de discussão para que os próprios catadores resgatassem o sentido de coletividade que estava perdido na ASCAMPA. Nascia assim a Clínica Psicodinâmica da Cooperação com este grupo.

Esta clínica acontece via criação de um espaço de discussão para dar voz ao sofrimento dos trabalhadores e, assim, potencializar a mobilização subjetiva do coletivo para a construção das regras sobre o fazer e o viver no espaço de trabalho (Mendes \& Araujo, 2012). Afinal, "trabalhar não é apenas produzir, é também viver junto" (Dejours, 2012, p. 85). Assim, a Clínica Psicodinâmica da Cooperação não é uma nova clínica, mas uma pesquisa-ação para trabalhadores que não adoeceram, mas que desejam falar sobre seu sofrimento no trabalho.

O termo sofrimento na Psicodinâmica do Trabalho tem sua origem na Psicanálise, na qual pathos se refere ao estudo do sofrimento e não apenas a doença (Moraes, 2013). Assim, "o sofrimento integra o trabalhar, visto que a experiência do trabalho inclui a vivência do fracasso, que faz sofrer. $\mathrm{O}$ sofrimento não é necessariamente patogênico; pode atuar como propulsor para mudanças" (Ibid., p. 418). É neste movimento de mudança e de mobilização, guiado pela cooperação, pelo próprio espaço de discussão, pelo uso da inteligência prática e do reconhecimento que converte o sofrimento em prazer.

A Clínica Psicodinâmica da Cooperação pretende ser promotora de saúde, com ação preventiva, pois esta mobilização do coletivo vai agir na organização do trabalho, como poderá ser visto na prática com os catadores aqui relatada.

Neste contexto, a mobilização subjetiva é o "processo que permite às pessoas utilizar sua subjetividade, recursos intelectuais e criatividade para transformar os aspectos da organização do trabalho que causam sofrimento e, assim, vivenciar o prazer" (Ferreira, 2007, p. 81). Neste processo, o sujeito pode (se) criar e (se) inventar. A mobilização subjetiva faz parte da concepção de trabalho para a Psicodinâmica do Trabalho, é o próprio trabalhar, como dito anteriormente.

O aporte teórico desta prática clínica advém da Psicodinâmica do Trabalho, que é uma clínica do trabalho: "investiga" o sujeito em situação real, concedendo um espaço privilegiado para a fala do trabalhador sobre seu sofrimento no trabalho, em uma perspectiva mais ontológica do que patológica (Lhuilier, 2011; Dejours, 2011; Mendes, 2007; Ghizoni, Mendes \& Corgozinho, 2013).

Ghizoni (2013) e Ghizoni, Mendes e Corgozinho (2013) apresentam estudos que privilegiam as práticas em Psicodinâmica do Trabalho no Brasil. As autoras ressaltam que no Brasil há adaptações ao método proposto por Dejours (2011), tal como Mendes e Araujo (2012) já haviam sinalizado.

Destaca-se que anterior aos estudos de Ghizoni (2013), somente Medeiros (2012), em seu estudo com trabalhadores da Unidade de Operações Aéreas do DETRAN, havia mencionado a prática clínica executada como uma Clínica Psicodinâmica da Cooperação. As demais práticas clínicas, tais como a de Santos-Júnior, Mendes e Araujo (2009), com grupos de bancários acometidos de LER/DORT; a de Gomes, Lima e Mendes (2011), que privilegiaram a escuta do sofrimento em sessões de clínica do trabalho com profissionais da área de treinamento e desenvolvimento de uma instituição do poder judiciário; a de Mendes, Alves e França (2011), com taquígrafos parlamentares; a de Silva e Mendes (2012), com servidores de uma agência reguladora; e a de Ferreira (2013), que realizou a intervenção clínica com os profissionais de Odontologia do centro ambulatorial de um hospital universitário, denominam apenas de intervenções em Psicodinâmica do Trabalho.

Acredita-se que a obra de Mendes e Araujo (2012) propiciou novas reflexões sobre o sujeito em ação em uma prática clínica em Psicodinâmica do Trabalho, o que tem reverberado novas considerações desde então, tal como este artigo, fruto da tese de Ghizoni (2013). 


\section{Método}

\section{Participantes}

Participaram desta prática clínica 16 catadores, sendo 9 homens e 7 mulheres, além de 2 jovens auxiliares. A grande maioria está na associação desde sua fundação em 2005. A idade dos participantes variou entre 39 e 78 anos. A maioria possui poucos anos de escolaridade, embora três já tenham concluído o ensino médio.

\section{Instrumentos}

Esta prática clínica seguiu as condições descritas por Mendes e Araujo (2012): 1. Organização da pesquisa; 2. Construção e análise da demanda; 3 . Instituição das regras de conduta do coletivo de pesquisa (uma clínica-pesquisadora, uma estagiária e os catadores voluntários) e do coletivo de supervisão (a clínica-pesquisadora, a estagiária e duas psicólogas); 4. Constituição do espaço da fala e da escuta; 5. Registros de dados: a) gravação do áudio (após autorização dos participantes), b) diário de campo individual, c) transcrição da sessão, d) supervisão e e) construção do memorial; 6. Apresentação dos relatos na reunião final; e 7. Avaliação da clínica. Os detalhamentos podem ser encontrados em Ghizoni (2013) e em Ghizoni e Mendes (2014).

\section{Procedimentos}

Houve uma reunião inicial (28 jan. 2012) para convidar os catadores a participar da prática clínica em que se contou com a participação de 13 dos 34 catadores associados. Foram realizadas 12 sessões entre os meses de fevereiro e junho de 2012 com a participação de 4 a 10 catadores por sessão. Cada sessão teve a duração média de 1h25. Um mês após a finalização da clínica, fezse a reunião de discussão do relatório final (6 jul. 2012), que contou com a participação de 11 catadores, para a qual se adotou o formato de pôster como forma de apresentar os resultados. Nove meses após esta reunião, fez-se uma entrevista coletiva para avaliar os efeitos da prática clínica após a saída das clínicas-pesquisadoras (5 abr. 2013), da qual participaram 9 catadores. Durante todo este processo, aconteceram 5 supervisões em Brasília (DF), 6 supervisões em Palmas (TO) (onde aconteceu a prática clínica), e 2 apresentações para discussões com o Grupo de Estudos do Laboratório de Psicodinâmica e Clínica do Trabalho da UnB. Como forma de devolução dos dados para a população pesquisada, fez-se uma apresentação geral dos resultados para os catadores da ASCAMPA no dia 28 de setembro de 2013, ocasião em que se entregou uma versão impressa da referida tese - estudo aprovado pelo Comitê de Ética e Pesquisas que envolvem seres humanos da Universidade Federal do Tocantins.

\section{Análise dos dados}

Devido à prática clínica ser fruto de uma tese de doutorado (Ghizoni, 2013), os resultados foram dispostos em três etapas, que compõem a Análise Clínica do Trabalho (Mendes \& Araujo, 2012): 1. Análise dos Dispositivos Clínicos; 2. Análise da Psicodinâmica do Trabalho dos catadores e 3. Análise da Mobilização do Coletivo de Trabalho, na Associação. Porém, o enfoque deste artigo centra-se na descrição da mobilização do coletivo da ASCAMPA e para tal serão considerados somente os dados da última etapa. Ao descrever a análise da mobilização do coletivo de trabalho, articula-se as dimensões que mais colaboraram para esta mobilização, sobretudo os dispositivos utilizados na condução da Clínica (análise da demanda, processos de elaboração e perlaboração, 
construção de laços afetivos, interpretação, formação do clínico-pesquisador e supervisão) e os três eixos da Análise Psicodinâmica do Trabalho (organização do trabalho, mobilização subjetiva e defesas). Os materiais utilizados para esta análise foram os Diários de Campo, os Memoriais, o Relatório Final, a transcrição do áudio da Reunião de Discussão do Relatório Final e a transcrição do áudio da Entrevista de Avaliação. Trata-se, portanto, de uma análise baseada nas interpretações destes documentos. Assim, os resultados são apresentados da seguinte forma: resumo das 12 sessões, descrição da Reunião de Discussão do Relatório Final e exposição dos pontos chave da Entrevista de Avaliação, para posterior discussão.

\section{Resultados}

Inicialmente, ao observar a organização do trabalho na ASCAMPA, sobretudo no tocante à gestão do empreendimento, via-se duas gestões convivendo concomitantemente: uma política, com a presidente e uma catadora que representava a associação nos movimentos sociais, e a outra administrativo-financeira, que fazia toda a gestão da associação, ou seja, comprava, vendia, negociava. Esta última lidava diretamente com os catadores, recebendo os materiais, pesando e pagando.

A presidente ocupava um papel secundário. Todos a reconheciam como presidente, mas todas as decisões eram tomadas pelo administrador da sede. Este fazia uma gestão centralizadora, que imprimia à associação um aspecto de empresa de ferro-velho, de "sucatão". As decisões, em sua maioria, eram tomadas unilateralmente: "Então na segunda-feira eu libero pra ele fazer o bico dele" (Transcrição da $4^{\text {a }}$ sessão, 10 mar. 2012). Esta atitude demonstrava o poder do administrador sobre o prensador, seu colega de trabalho na sede, um catador também associado e no prescrito com poderes iguais.

Ao longo das sessões, o administrador foi tentando imprimir o que ele gostaria que fosse a Associação, embora houvesse contradições na sua prática. Os demais catadores, por sua vez, demonstravam descontentamento com esta forma de gestão da ASCAMPA; a própria equipe que atuava na sede da Associação reclamava de sobrecarga e se negava a fazer tarefas importantes, mas desgastantes, como o controle da pesagem de cada catador e também a negociação e a venda dos materiais em grande quantidade.

Neste cenário, apresenta-se os resultados deste estudo em três etapas: o resumo das 12 sessões da Clínica Psicodinâmica do Trabalho (fevereiro a junho de 2012), os dados da reunião de discussão do relatório final (julho de 2012) e os avanços e desafios percebidos na reunião de avaliação da Clínica Psicodinâmica da Cooperação (maio de 2013).

\section{Resumo das sessões da prática clínica}

Da primeira à terceira sessão, os catadores relataram sua rotina de trabalho, fizeram queixas e demandaram por um "outro" para resolver seus problemas. A clínica-pesquisadora encontrou dificuldades com o real da prática clínica e mobilizou-se formando um coletivo de supervisão local.

Da quarta à sexta sessão, observou-se um crescimento do grupo. Começaram a falar das fragilidades do coletivo de trabalho, das formas de sofrimento, dos medos, das formas de manifestação do estresse, das dificuldades com a divisão das tarefas e das diferenças individuais.

Observou-se também que a formação da clínica-pesquisadora e a supervisão perpassam todo o processo de mobilização do coletivo de catadores e também do coletivo de pesquisadores. Escutar o sofrimento implicou dividir as angústias deste processo com o coletivo de pesquisadores. Foi neste momento da clínica que o coletivo de clínicos-pesquisadores se instaurou em Palmas 
(TO) e discutiu formas de como levar o grupo de catadores a fazer um enfrentamento com o administrador da sede.

Da sétima à nona sessão, os incômodos com a administração da ASCAMPA se acentuaram e foram externalizados. Houve enfrentamentos com o administrador da sede, permeados pela desconfiança e pela coragem. Começaram a se reunir para discutir a organização do trabalho.

A sétima e a oitava sessão não contaram com a presença do administrador da sede, o que acabou por provocar muitas falas importantes, sobretudo para que os catadores pudessem perceber que poderiam se organizar em um coletivo sem o poder centralizador do administrador. E assim começaram a fazer reuniões, tanto após as sessões de clínica quanto na sede da associação, culminando com a criação de um coletivo gestor que passou a entender e organizar os processos de trabalho dentro da ASCAMPA.

A nona sessão, embora com poucos participantes, foi a sessão em que aconteceu o enfrentamento com o administrador da sede. Percebeu-se que a mobilização acontecia por meio da decisão tomada pelos catadores de vencer os medos e reafirmar o que haviam dito nas duas sessões anteriores. As estratégias de defesa do administrador, de vitimização e de justificação de todas as críticas recebidas não afetaram todos os catadores, alguns seguiam decididos na reorganização coletiva da associação, incluindo-o apesar das dificuldades. Assim, o momento configurou-se pela passagem do grupo das discussões para as deliberações, embora com algumas ressalvas da clínicapesquisadora naquele período.

Na décima e na 11aㅗ sessão, percebeu-se que as deliberações foram acontecendo no dia a dia da ASCAMPA. Formaram um coletivo gestor composto por quatro catadores que antes atuavam somente nas ruas, que se uniram e passaram a trabalhar dentro da sede com o administrador, o prensador e o pesador/anotador. Assim, criaram, coletivamente, regras de trabalho e de convivência.

Formaram um coletivo de trabalho e começaram a colocar a "mão na massa" na sede da associação. Antes eram 4 pessoas para atuar na sede ( 1 administrador, 1 prensador e 2 jovens auxiliares), agora chegaram mais 4 integrantes catadores, formando um coletivo de 7 pessoas (Relatório Final, 6 jul. 2012).

Se nas sessões anteriores o enfrentamento tinha sido verbal, os conteúdos trazidos nestas duas sessões se caracterizaram pelo conflito na gestão da ASCAMPA. O velho e o novo jeito de administrar: um consolidado e que os catadores não aceitam mais, e outro ainda confuso, em construção.

A inovação não perpassou somente as questões administrativas e de processos de trabalho, mas também da necessidade de lidar com mulheres ocupando o mesmo espaço, anteriormente eminentemente masculino.

Percebeu-se a comunicação entre os catadores ainda truculenta e, em vários momentos, agressiva. Acabou-se por perceber que discutir regras onde não havia regra alguma se tornava uma tarefa bem difícil para o coletivo de trabalho, sobretudo por ser a primeira experiência de tê-las e de habituar-se a regras de trabalho e convivência. Como houve pouca discussão sobre tais regras, os próprios catadores começaram a negar tais normas e, assim, tentam atingir a catadora que escreveu o cartaz, afirmando que ela era "mandona" e que eles não iriam aceitar este tipo de atitude.

Nesse momento, os catadores tiveram dificuldades para perceber que eles podiam criar as regras, experimentá-las e fazer novas regras como desejassem. Mas esta liberdade para administrar os inibiu e acabaram por repetir comportamentos do antigo administrador, assim como ainda deixaram com ele o controle dos pagamentos para os catadores, embora em discordância com a forma como ele fazia.

Assumir os riscos e as responsabilidades ainda era uma tarefa difícil para o coletivo gestor, lembrando que este coletivo era formado por catadores que valorizavam justamente a liberdade da 
catação nas ruas, a construção de seus horários e o fato de não terem patrão. Acreditava-se que os catadores do coletivo gestor necessitariam de um tempo maior para esta adaptação que, talvez, não coincidisse com o final da clínica.

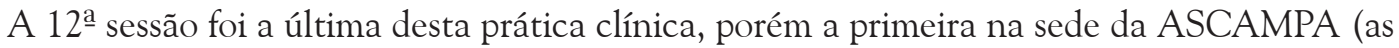
anteriores foram realizadas em uma instituição parceira da associação, por opção dos próprios catadores), o que demarcou a força do coletivo gestor, mobilizado em promover mudanças na organização do trabalho da associação. Mesmo sendo a última sessão, o Grupo relatou a necessidade de melhorar os controles financeiros da associação, torná-los mais transparentes. Porém, o que se observou na época foi muita resistência quanto a quem iria ocupar esta função.

A clínica terminou, mas a mobilização do coletivo de catadores continua, novas demandas surgem e não se sabe que rumos a organização do trabalho da ASCAMPA vai tomar. Este é o vir a ser da clínica, no seu durante e no seu após.

Observou-se a mudança na forma de se verem e verem o coletivo da associação. No início, reclamavam que eram poucos, fracos, individualistas, mas ao final diziam:

"É muito interessante... de se organizar porque a gente achava assim difícil, mas tudo tem solução, basta ter o consenso que depende de cada um de nós, a união faz a força, a gente sozinho não consegue... nós temos que aprender a confiar um no outro... [o] trabalho nos melhora a cada dia mais, então estamos de parabéns, a gente esta de parabéns mesmo quando falamos que somos poucos, mas uns poucos que acreditam" (Transcrição da reunião de discussão do relatório final, 6 jul. 2012).

A confiança como base para a cooperação foi percebida pelos catadores e, assim, reconhecida nesta reunião, o que é muito importante para a continuidade da mobilização do coletivo.

\section{Reunião de discussão do relatório final}

Na reunião de discussão do relatório final, realizada trinta dias após a última sessão, ainda foram pontuados elementos que precisam ser trabalhados pelo coletivo: "Acho que falta empenho, ação, vontade de trabalhar, porque isso aqui não adianta, tem que entrar aqui, tem que trabalhar, aqui não é brinquedo não, tem muito serviço. É isso que eu penso" (Transcrição da reunião de discussão do relatório final, 6 jul. 2012).

Resgataram a necessidade da confiança no grupo, algo ainda em construção. Percebeu-se que os catadores vêm trabalhando há mais de sete anos envoltos em desconfiança e individualismo, mudar esta relação é uma construção que os catadores estão tentando. Já perceberam que esta confiança, união, cooperação e solidariedade depende deles:

Quem tem de confiar um no outro é o grupo mesmo, não sou que vou fazer pro [prenseiro] confiar em mim, e nenhum de nós, é cada um fazer o seu certo como é pra ser, corrigir o que está errado... No outro dia que nós estivemos na reunião aqui, eu falei: nós estamos aqui pra nos unirmos e trabalharmos juntos, nós estamos aqui pra corrigir um ao outro, onde ver que um está errado, o outro do grupo pode chegar naquela pessoa, não é feio.... Estamos aqui pra ajudar um ao outro em toda situação" (Transcrição da reunião de discussão do relatório final, 6 jul. 2012).

O coletivo gestor, que começou voluntariamente (embora com certa desconfiança das clínicas-pesquisadoras sobre a fragilidade deste vínculo) deu muito certo, a ponto de o primeiro mês ser citado como o momento em que os catadores mais produziram, mais se organizaram. $\mathrm{E}$ com o passar do segundo mês, decaíram na produção e nos cumprimentos de horários de chegada e saída. 
Através da prática, o coletivo gestor começou a se dar conta das diferenças entre ser catador nas ruas e ser um catador que atua na sede. As exigências da atividade são diferentes, a começar pelo controle dos horários e pelo senso de coletividade:

Catador tem horário sim, pra sair pra catar ele sai tal hora, pra sair pra separar o material dele ele faz tal hora, aqui nós não somos catadores... aqui nós somos recicladores, nós que vamos dar fim pro produto final, e tem que ter um horário, porque senão... (Transcrição da reunião de discussão do relatório final, 6 jul. 2012).

Mesmo com a prática, ao explicar as diferenças entre os grupos, os catadores que atuam na sede se confundem, pois não são recicladores, como afirmam, eles não transformam o material, eles o separam e vendem para alguém que irá reciclar. Um trabalho muito semelhante ao que os ferrosvelhos e sucateiros fazem, a diferença está na organização do trabalho, que tende a ser coletivista, com catadores se apropriando de todo o processo produtivo, e não individualista e mercantil, com relações de servidão. A ASCAMPA vive este processo de transição entre ser uma organização de produção coletivista de verdade e ter uma gestão ainda nos moldes mercantilistas de servidão.

Atuando na sede o coletivo gestor aprendeu coisas novas, como separação de papéis brancos, formas mais fácies e ágeis de se tirar capas de cadernos ou livros etc. As práticas individuais iam se contrastando, e alguns ainda tinham dificuldades para falar o que consideram ser certo. Mas, aos poucos, foram se colocando e aprendendo uns com a experiência dos outros. Toda a inventividade da inteligência prática sendo vivenciada por pessoas que já tinham experiência na catação e separação de materiais, mas que sozinhos faziam de maneiras diferentes e, em alguns casos, até desnecessariamente: "Eu vou mudar a minha atitude de separação, só branco... A gente pode trabalhar quanto for, sempre tem uma novidade.... [um catador me falou] 'isso daqui é PP', eu lá sabia o que é PP, pra mim só tinha PAD” (Transcrição da reunião de discussão do relatório final, 6 jul. 2012).

Foi interessante perceber na reunião de discussão do relatório final que eles avançavam com um olhar para o futuro, trazendo os problemas que tinham vivenciado e refletindo sobre como poderiam superá-los. A principal questão citada foi a forma de pagamento. Não havia consenso entre os catadores se é melhor ganhar por produção ou por diária. Alguns, inclusive, não sabiam o que era ganhar por produção e outros explicaram. Receber por produção seria ganhar pelo que conseguiu separar ao final do dia, seria fruto de seu trabalho individual. Ao passo que a diária inclui um pagamento fixo, independente do tipo de serviço realizado. Uma boa parte dos catadores acha que a diária paga pela associação é muito baixa, tornando inviável deixar de catar nas ruas para atuar na sede da ASCAMPA. Assim, um dos catadores do coletivo gestor sugeriu fazer um teste para avaliar e, então, com base na prática, discutir novamente:

[Em] primeiro lugar, amanhã, eu vou fazer um piloto, eu vou na coleta, eu vou coletar o dia inteiro como diária, eu vou coletar o dia inteiro. Tá, [vou] coletar como se eu estivesse catando na rua, vou pesar pra ver se realmente compensa. Então, não adianta a gente falar em valores agora, porque isso é bobeira, tem de ver se compensa, porque eu tenho uma certa agilidade, uma certa prática (Transcrição da reunião de discussão do relatório final, 6 jul. 2012).

Os demais catadores concordaram com esta experiência, embora pontuassem que há ritmos muito diferentes de trabalho. Alguns catadores são mais ágeis que outros e na diária parece que estas diferenças se acentuam.

Destarte, com a inteligência prática em ação, encerrou-se a Reunião de Discussão do Relatório Final. Percebeu-se que o confronto com a realidade do trabalho na gestão da ASCAMPA disparou 
elementos das subjetividades que ainda não haviam sido tratados ou que precisam da repetição para uma possível perlaboração. Ao fazerem isto, se engajaram cada vez mais na organização do trabalho da ASCAMPA, a qual prescinde de ajustes conforme a mobilização vai acontecendo.

\section{Reunião de avaliação da clínica psicodinâmica da cooperação}

Este é o primeiro estudo que conta com esta avaliação alguns meses após a realização da clínica, tal como sugerem Mendes e Araujo (2012). Tal reunião de avaliação foi realizada no dia 5 de abril de 2013, nove meses após a discussão do relatório final, no dia 6 de julho de 2012. Nesse espaço de tempo, a clínica-pesquisadora fez algumas visitas à sede para manter os vínculos, embora todos os encontros tenham sido informais. No período de setembro de 2012 a janeiro de 2013, a clínica-pesquisadora realizou seu estágio-sanduíche na Bélgica, afastando-se da associação. No retorno, em janeiro de 2013, surpreendeu-se ao visitar a sede da ASCAMPA: estava desocupada, com pouquíssimos materiais acumulados em volta. Então, apareceu um catador (do coletivo gestor), antigo morador daquela sede, que a acolheu muito bem e avisou que estavam de mudança naqueles dias para o novo espaço da associação, o tão sonhado terreno com muro, concedido pela prefeitura de Palmas (TO).

A clínica-pesquisadora dirigiu-se imediatamente ao novo local e foi igualmente muito bem recebida pelos catadores que lá estavam. Percebeu-se que a presidente da associação havia tomado a frente de toda a organização junto de outros dois catadores do antigo coletivo gestor. Agregaram-se ao grupo outros catadores, alguns novos e outros já participantes da Clínica Psicodinâmica da Cooperação.

A impressão neste dia foi de que o trabalho coletivo estava acontecendo, havia muitos materiais dispostos no local, algumas máquinas novas, mas ainda muita precariedade. Estavam sentados em locais inapropriados, embaixo de uma árvore, fazendo a separação dos materiais. Informaram-na que uma cozinha seria construída assim como um banheiro.

A clínica-pesquisadora voltou outras vezes e as mudanças eram perceptíveis a cada visita: uniformes novos, uma grande tenda para abrigá-los do sol e da chuva, uma casa improvisada para um dos catadores morar e cuidar da sede. A cozinha estava construída, embora bem precariamente, o banheiro também foi improvisado, com tapumes. Afirmavam usar o banheiro do supermercado vizinho à associação. Em uma destas visitas, agendou-se a reunião de avaliação, para que o grupo pudesse falar sobre as mudanças que foram acontecendo ao longo dos meses.

A reunião aconteceu na nova sede, começou pontualmente no horário determinado, com a presença inicial de oito catadores - seis dos quais haviam participado da Clínica Psicodinâmica da Cooperação e dois eram novos na ASCAMPA. Do coletivo gestor inicial, o prensador, o administrador e o jovem auxiliar tinham deixado a associação, os demais haviam permanecido.

Começaram relatando as conquistas: "O terreno, luvas, maquinário". Assim como fizeram questão de frisar que não era uma vitória de nove meses, como havia sido pontuado, mas do início das atividades do coletivo gestor na sede da ASCAMPA: "Tá fazendo um ano agora, no dia 7 de maio. Completa um ano essa nova vitória, uma vitória de cinco anos atrás".

Um dos catadores demarcou este momento do início do coletivo gestor com uma metáfora: "Quando o grupo entrou. Quando os Quatro Cavaleiros do Apocalipse entraram...". Os Quatro Cavaleiros são personagens descritos na terceira visão profética do apóstolo João no livro bíblico de Revelação ou Apocalipse: Peste, Guerra, Fome e Morte. Interpreta-se que o uso da metáfora pode ter sido usado para designar todo o sofrimento que passaram neste tempo, pois pontuaram conquistas, como o fato de as mulheres terem entrado na gestão da ASCAMPA, embora ainda tenham um longo caminho pela frente: "[É] que lá embaixo as mulheres não podiam entrar, entendeu? As mulheres não tinham vez, entendeu? Aí se formou esse grupo pra entrar. Não melhoramos muita coisa não, ainda estamos de marcha ré". 
A questão do relacionamento entre a antiga administração e as mulheres do coletivo gestor sempre foi tensa e pareceu piorar que com o passar do tempo: "E as mulheres tinham que obedecer a ele, fazer o que ele queria. Dizia que nós estávamos brincando de administrar, que a gente não ia aguentar três meses. Com três meses nós saíamos. Nós não saberíamos administrar”. A forma de agir desafiadora do antigo administrador da sede continuou a permear as relações, ampliando o abismo nestas relações socioprofissionais.

Os catadores enumeraram as seguintes vitórias:

Primeiro, não temos mais aquele problema de furto, drogas... É um ambiente de confiança... A vitória maior e mais forte mesmo... foi tirar a pessoa que o povo lutava pra tirar e não conseguia. Entrava um, não conseguia. Entrava outro, não conseguia. A [articuladora do movimento] chegou a dizer para alguns que chegavam perto dela assim: "Quem? Ninguém tem coragem de ocupar o lugar dele, né?" E hoje está aí uma realidade diferente do que a [articuladora do movimento] achava, que ninguém era capaz de ocupar o lugar dele.

Ao que pareceu, a conquista do controle administrativo-financeiro da ASCAMPA os empoderou e não foi possível conciliar isso com a presença do antigo administrador, ao qual eles se referem acima. Há um sentimento de libertação. Citam medos que não haviam manifestado ainda, como o medo de serem repreendidos pelos órgãos da polícia devido ao uso e possível armazenamento de drogas na sede.

Fazem uso de outra metáfora para dizer o quanto ainda estão aprendendo neste ofício de gestores. Estão na atividade sem o antigo administrador há 3 meses: "Agora nós temos tudo na mão: faca, o queijo é só cortar, saber cortar é que nós ainda não estamos sabendo".

Os motivos alegados para o rompimento com antigo administrador foram: "Ele não aceitava a nossa presença", a presença das mulheres, afirmou que "ia matar as mulheres na unha, entendeu? Só que ele está morrendo na unha, tá". O antigo administrador queria entrar na diretoria da cooperativa que estavam criando, porém o grupo não aceitou quando percebeu que ele estava emperrando todo o processo de transição do antigo espaço para este novo:

Se ele da Ascampa, ele fez o que fez, o que ele tinha que fazer na cooperativa? Então ali já foi tirado. Agora, recentemente, aqui em cima, ele foi também excluído devido que ele não assinou aos papeis, tá? Por causa dele que demorou muito, demorou tudo, tá, que ele não queria assinar os papéis.

Confirmaram que a saída do antigo administrador foi protocolada em cartório. Com este detalhe, percebeu-se que começaram a se atentar para as normas da associação, antes não observadas.

Ao tomarem conhecimento da real situação financeira, os catadores perceberam que o aluguel do terreno que ocupavam estava atrasado há dez meses: "Três mil e setecentos reais de aluguel sem pagar. E nós vamos pagar, nós estamos devendo". No entanto, o administrador hesitava em colaborar com coletivo gestor: "Ele chegou batendo o pé, professora, que não existe nenhum associado que vai saber de administração melhor do que ele, porque ele não deixava a água atrasar nem o dinheiro atrasar".

O coletivo gestor assumiu a associação, a criação de uma cooperativa e as dívidas. Relataram que apareceram muitas contas para a associação pagar como também máquinas que quebraram, tanto a balança quanto a prensa:

No dia que eu peguei o primeiro dinheiro de lá do caixa, daí o café não tinha para beber. Para fazer um cafezinho para a gente tomar. Água atrasada, comida de jeito nenhum, só pão a gente comia... Quando nós estávamos no auge de mudar, quebrou a prensa de novo, então, aí vai só acumulando. 
Os catadores demonstraram apropriação de um saber que antes era exclusivo de um catador que operava a prensa: "Lá embaixo todo mundo tinha medo da prensa, hoje até as mulheres, se quiserem, operam a prensa... Mas antes todo mundo tinha medo da prensa. A galera achava que a prensa é um bicho de sete cabeças".

Os catadores listaram os equipamentos que ganharam via editais da FUNASA e CATAFORTE após sua chegada à nova sede: "Uma empilhadeira, uma esteira, três carrinhos de mão... uma balança de mil quilos, a esteira... uma tenda”. Esta última eles receberam de uma empresa de refrigerantes e da prefeitura de Palmas. Citaram também um caminhão que ainda iria chegar: "Temos um caminhão, até o dia 18 ele já está aqui".

Falaram da criação da COOPCAMPA, a cooperativa que estavam criando. Sentiram dificuldades para falar dos cargos, não lembravam as funções e misturavam com os cargos da ASCAMPA - eram as mesmas pessoas exercendo atividades diferentes na cooperativa. Assim como falaram ter esquecido o significado de COOPCAMPA: "Eu não lembro mais não. Nós não decoramos". Como o processo ainda era muito recente, percebeu-se que os catadores ainda não haviam se apropriado da nova cooperativa como um todo.

A intenção dos catadores era continuar com as duas organizações, a ASCAMPA e a COOPCAMPA: "Parece que muitos projetos vão ser encaminhados para a cooperativa, então a ASCAMPA não pode morrer".

A presidente de ambas as organizações era a mesma que já atuava como presidente na ASCAMPA há três anos, mas relatou:

É, três anos, porque o primeiro foi dois anos, só que os dois anos eu não pude ficar lá dentro [da sede], eu era assim de participava de reunião, de assinar papel, mas eu não tive essa oportunidade de ficar lá dentro. Nem sabia a realidade.

Observou-se o avanço desta catadora, que no último ano apropriou-se do seu lugar. Lembrando que era uma catadora que tinha medo de se expressar e que foi demandada a participar mais desde a reunião para o convite da clínica da cooperação. E assim ela fez: agiu, ousou, superou-se, mobilizou-se. Usaram uma metáfora para explicar esse processo: "Ela era Itamar, agora ela é Lula". Ela explicou seu empoderamento e afirmou: "Eu tenho consciência do que eu estou fazendo".

Precisavam ainda discutir de maneira mais aprofundada as regras de funcionamento da COOPCAMPA, sobretudo o cumprimento de horários - "Tem de ter horário, tem que ter, tem gente que não admite, não aceita, mas não pode ficar assim sem regra” - e as formas de pagamento - "Porque a gente tem dificuldade em tudo, principalmente no pagamento, que é onde a gente tá encontrando muita dificuldade". Por outro lado, começaram a usar estratégias diferentes para algumas atividades antigas:

"Nós usamos um método de trabalho com alguma coisa tipo, quem tem muito material que é o caso dele, tá? Ele tem muito material e as pessoas que têm bastante material, a gente está tentando, com a pessoa, pra ajudar na prensa".

Esta ideia foi dada pelo catador que mais traz papelão para a associação vender (o que é importante, pois gera receita e pode aumentar as sobras), assim, pareceu que o catador deixou de somente depositar o material na sede, implicando-se com as ações dentro da ASCAMPA/ COOCAMPA - eis o engajamento no trabalho coletivo se concretizando.

As diferenças individuais e a imposição do pensamento individual sobre os demais com pouca discussão ainda eram questões que os catadores precisavam enfrentar. Indagados sobre o espaço 
de discussão, sobre as reuniões do coletivo gestor para conversar sobre as questões que precisavam avaliar e decidir melhor, afirmaram que na sede antiga, "quando estávamos em grupo de quatro, todas as sextas-feiras nos reuníamos, conversávamos, discutíamos. Caçava ideias, opiniões e tudo, mas hoje não acontece mais isso". Havia contradições quanto a essas reuniões não estarem mais acontecendo: alguns alegaram "esquecimento", outros disseram que não era isso e sim "que aqui ninguém quer mais ideia nem opinião de ninguém". Mas houve discordâncias também quanto a essa opinião: justificaram com a mudança o novo ritmo de trabalho que estavam tentando impor e que as condições físicas da nova sede não estava permitindo:

Eu não concordo, não. Acho que é o tempo da gente querendo trabalhar mais e mais e tá faltando esse tempo pra reunião. Porque é isso que a gente tem que ter. Deixar o trabalho e se reunir sentar e conversar. Em primeiro lugar não tínhamos um local que era na chuva ali. Quando passamos pra cá foi debaixo de chuva. Só que agora nós temos esse local aqui e nós poderemos voltar ao mesmo sistema que nós adotamos lá embaixo. Toda sexta-feira, depois das três, nós sentamos e discutimos e vemos qual é o melhor pro grupo e associação, todo mundo junto.

Essa falta de espaço de discussão fez ressurgir o velho problema da falta de pagamentos ou da incerteza de como, quanto e quando iriam receber. Recorrência avaliada por eles mesmos como a forma que escolheram para pagar os catadores. $\mathrm{Na}$ antiga sede, haviam decidido pelo pagamento coletivo, dividido igualmente. Inclusive, havia sido tema da reunião de discussão do relatório final. Fizeram desta forma por três meses e funcionou bem. Os trabalhadores da sede ganhavam um salário mínimo, independentemente da quantidade de dias trabalhados ou do material separado:

Os três primeiros meses deu ótimo isso. Funcionou bem. Pagou todo mundo e estava tudo "ok". Só que foram três meses. De lá pra cá não funcionou mais. Porque não deu mesmo. Nós encontramos muita coleta acumulada e aí dessa coleta surgiu esse dinheiro que desse pra pagar um salário [R $\$ 622,00]$ pra cada um.

No entanto, diante desta experiência e das diferenças de ritmo de trabalho, sobretudo das dificuldades para cumprir horário, discutiram a possibilidade de os pagamentos serem feitos por produção: "Por exemplo: 'O que eu coletar é meu'. Vou anotar e vou ganhar por aquilo que eu fiz". Observou-se esta prática com cuidado, pois pôde fortalecer no grupo ações individualistas, tentando buscar a construção de laços coletivistas. Porém, compreendeu-se que decisões como essa fazem parte do processo de construção de qualquer associação, pois envolve tomar a decisão, experimentar, avaliar e refazer se for necessário. Há liberdade para isso no modelo de gestão associativista.

Com relação a essas questões que envolvem a forma de pagamento, a articuladora do Movimento Estadual dos Catadores expôs sua opinião:

Eu sempre fico desconfiada e perguntando como é que esse troço [a associação] funciona, porque até hoje a gente não entendeu como é que trabalha, né? Você sabe que a gente primeiro tem que ser gerado, aprender a caminhar, aprender a falar, né?

Através desta metáfora ela tentou mostrar para o grupo a paciência com as etapas, que todos ainda estão aprendendo a fazer a organização administrativo-financeira da ASCAMPA, que estão há poucos meses no comando da associação, o que implica novos saberes. Essa catadora cita um exemplo originário de sua participação em um congresso de catadores, onde ouviu que a maioria 
dos catadores das associações e cooperativas recebem através da porcentagem retirada da venda do material: "Tinha que fazer, tudo era por porcentagem, porque senão a soma... Todo mundo desde catador, desde administrador tinha que ganhar por porcentagem...”. Ao pesar seu material, cada catador deixaria uma porcentagem para gerir a associação e, assim, pagar os salários dos que atuam dentro da sede.

Esta forma de pagamentos por porcentagem era adotada pelo antigo administrador, embora não muito corretamente, já que descontava porcentagens diferentes entre os catadores. Ao que pareceu, os catadores não sabiam o que era ou como fazer um pagamento por porcentagem.

Outro problema percebido foi que, com a mudança da gestão municipal, responsável pela coleta seletiva em algumas quadras da cidade, esta deixou de ser periódica, nem se sabia se o projeto ia ter continuidade, uma vez que era experimental. Os catadores contavam com aquele material para o pagamento de seus salários: "É porque a coleta... Aliás, ela tá faltando até semana. Tem semana que não...”. A mudança na quantidade de material implicou a falta de pagamento de mais de um mês para os catadores, alguns não recebiam há três meses, outro aspecto recorrente da gestão anterior: "Agora tem que sentar todo mundo e fazer por porcentagem, porque aí vai dar o dinheiro pra todo mundo no final do mês. [...] Eu não aguento mais ser voluntária porque eu também preciso me manter".

Uma das catadoras novas na associação pediu urgência com as decisões, sobretudo no que tange à divisão de tarefas e à forma de pagamento:

Eu acho que a gente tem que, o mais rápido possível, ver como nós vamos trabalhar, nós estamos aqui e nós estamos precisando, né? Fazer uma reunião é ver quem vai pra tal lugar, quem faz tal [coisa], tem a função certinha, "fulano você é pra isso", entendeu?

A presidente, por sua vez, apresentou uma série de atividades que ela desempenha para gerenciar a associação e que não tem forma de pagamento definida. Assim, uma catadora sugeriu que para esse trabalho bem como para o prensador deveria ter um salário fixo: "Será que não seria melhor ela ter um salário [pelo] que ela faz aqui dentro?". Ampliou-se a discussão para o trabalho de articulação que uma das catadoras faz, ressaltando a importância do trabalho e, consequentemente, que os catadores refletissem sobre como remunerá-la, pois "ela vai buscar experiência pra ela e pro grupo".

O grupo demonstrou muita confiança na gestão financeira que a presidente vem fazendo, embora ela ainda não saiba como fazê-la corretamente, mas o grupo sabe e tenta ajudá-la: "A parte da honestidade aqui ninguém nem julga... Ela é a ideal mesmo, passa fome, mas não tira o dinheiro do caixa”. Ressaltou-se nesta atitude um grande crescimento do grupo, pois além de terem assumido esta gestão financeira, embora com muitos problemas de pagamento, criaram um elo de confiança imprescindível para a cooperação. Percebeu-se que a cooperação tem acontecido, pois mesmo sem salários, devido a todos os entraves que tiveram, continuavam trabalhando e acreditando no coletivo.

Observou-se que neste processo de mobilização os catadores visualizavam as dificuldades e experimentavam novas regras, mas ainda não conseguiam uma forma de organização de trabalho que gerasse mais recursos para eles. Porém, não desacreditaram e avançaram no sentido de perceberem a necessidade de progredirem enquanto grupo:

Eu acredito que como cooperativa, como as regras são diferentes, com o caminhão, nós vamos ter mais recursos, porque tipo assim, que nem uma vez nós tava conversando,... que a gente está precisando é caminhar com as nossas próprias pernas, até hoje nós estamos caminhado com as pernas de Prefeitura, de Kolping, não! Caminhar com as nossas próprias pernas, sabe?

\section{8}




\section{Discussão}

Observa-se no contexto deste estudo a indissociabilidade entre prazer e sofrimento no trabalho, como postulou Dejours (2004). Considera-se o prazer como "um princípio mobilizador da dinâmica que emerge dos contextos de trabalho" (Mendes \& Muller, 2013, p. 289) e isso foi percebido nesse grupo de catadores, que lidou com o real: os trabalhadores se colocaram em ação para buscar a realização e o reconhecimento. O sofrimento, por sua vez, é inerente ao ato de trabalhar, como também afirmou Dejours (2011), pois o conflito entre a organização do trabalho no caso da ASCAMPA é conviver com as normas que envolvem a gestão da catação, separação e venda dos materiais recicláveis, com o desejo dos catadores de ver uma cooperativa nascer desse coletivo de trabalhadores.

O real do trabalho dos catadores da ASCAMPA passa por um processo de mudança ao longo das sessões. $\mathrm{O}$ que antes era individual passa a ser coletivo. A criação do coletivo gestor durante a realização da clínica demarcou a passagem das discussões para as deliberações, uma etapa imprescindível para a mobilização subjetiva acontecer.

É importante observar que se trata de uma categoria profissional que nasce dos restos, daquilo que a população não quer mais, e que, portanto, rejeita, descarta, joga no lixo. É desta "sobra" que os catadores sobrevivem. Tal sujeição da condição humana os torna vulneráveis. Os catadores viviam como uma associação, mas no real a vivência era de servidão, pois não detinham os conhecimentos sobre todo o processo de trabalho e ocupavam-se somente da etapa da cadeia produtiva que recolhe o material nas ruas, de forma individual. Acomodação que favorecia a servidão voluntária dos catadores, pois, mesmo não concordando com as práticas, silenciavam. Tal situação reflete o que pensa Mendes (2008): a sobrevivência, a segurança e o poder são dimensões da condição humana e acabam por fortalecer a sujeição dos trabalhadores, independentemente do tipo de organização que constituem.

São trabalhadores que vivem um histórico de exclusão, tal como pontuam Medeiros e Macêdo (2006) e Carvalho (2008), que sociedade rechaça e os colegas, por agirem individualmente, são muitas vezes concorrentes, mesmo fazendo parte de uma mesma associação. Como se verificou no decorrer das sessões com o grupo, a concorrência é pela coleta de material nas ruas: quem chega primeiro leva.

Ressalta-se, assim, a relação do individualismo e da concorrência presente nas organizações de produção associada, assim como nas organizações capitalistas. Inicialmente, interpretou-se esse movimento como uma contradição, mas depois avaliou-se que não cabem julgamentos, pois viver sob a égide do sistema capitalista acaba por imprimir esse modelo nas relações que envolvem o trabalho. Assim, a contradição faz parte da construção da gestão de todo empreendimento de natureza associativista, em que os trabalhadores têm a posse coletiva dos meios de produção e a organização do trabalho é regulada pela prática do coletivo, que detém o poder de decisão, afinal, os trabalhadores se associam para a produção de bens e serviços a favor do coletivo (Tiriba, 2007; Tiriba \& Fischer, s.d.).

Bortoli (2009) também observou entre os catadores cooperativados de Cruz Alta (RS) interesses individuais, pouca participação, oportunismos, práticas clientelistas e demanda por um "ente" que resolveria todos os problemas. Para o autor, é comum esse movimento na categoria de catadores por não possuírem uma história de participação em movimentos sociais e de clareza da subsunção do capital a que estão submetidos. Pontua-se, entretanto, que os interesses individuais tendem a existir onde há trabalhadores interagindo, e esse movimento, ainda que seja frágil, é concreto, é real, é decidido pelos próprios trabalhadores, e isso é o que faz nascer a gestão com a cara do empreendimento.

Percebeu-se nesta clínica com os catadores que a criação do espaço de discussão propiciou a quebra do silêncio e do individualismo, favorecendo a mobilização de um coletivo gestor para 
implementar mudanças na organização do trabalho da ASCAMPA. Bortoli (2009) também criou espaços de discussão entre catadores, embora não em clínica do trabalho, e ao longo de dois anos de projeto propiciou o intercâmbio de experiências entre catadores do estado do Rio Grande do Sul. Movimentos como este, para viabilizar a fala, a escuta, o encontro, a confiança e a discussão, são imprescindíveis para a construção de um coletivo, na tentativa de mudar a lógica do individualismo.

Criar um espaço de discussão no ambiente de trabalho para que se dê vazão ao sofrimento vivenciado na organização do trabalho não é tarefa fácil, embora o trabalhar seja o encontro do sujeito com o fracasso e, portanto, uma experiência de sofrimento (Moraes, 2013). Em seu estudo, Ferreira (2013) salienta que embora o grupo de profissionais da odontologia tenha reuniões periódicas, não há espaço de discussão e deliberação no coletivo, prejudicando a cooperação e consequentemente a mobilização. Ferreira, Mendes, Lima, Facas e Ghizoni (2013) explicitam que na falta de um espaço de discussão para os impasses vinculados ao trabalhar não há debate nem elaboração, restando somente o uso das defesas como estratégia para evitar o adoecimento. Tal situação ocorreu entre as cuidadoras sociais de um abrigo, que acabaram por criar um distanciamento afetivo entre elas e o usuário (Lima, 2011). Medeiros (2012) observou que o grupo de pilotos de helicóptero já havia tentado criar um espaço para discussões sobre o relacionamento entre os trabalhadores, pois percebiam a necessidade de melhorar a convivência no ambiente de trabalho, porém não conseguiram sozinhos. A intermediação de um clínico-pesquisador pode disparar esse desejo de falar, ouvir, repensar novas práticas e dar vida à inteligência prática e, por consequência, pode transformar sofrimento em prazer. Merlo, Dornelles, Bottega e Trentini (2012), após investigação sobre os efeitos do trabalho à saúde dos oficiais de Justiça Federal de Porto Alegre, sugeriram a criação de um espaço de discussão que envolva esses trabalhadores para que possam falar sobre o sofrimento vivenciado na organização do trabalho.

Observou-se que ter um espaço de discussão estabelecido entre os catadores trouxe grandes mudanças para a organização do trabalho da ASCAMPA e para a vida dos catadores. Houve oportunidades para repensarem práticas, visões e atitudes bem como a possibilidade de experienciarem a sensação de ser escutado "por um outro que se posiciona de maneira aberta para realizar essa escuta, para interagir e discutir o que foi vivido pelo sujeito quando em contato com o trabalho" (Mendes \& Araujo, 2012, p. 129). A presença deste "outro" é fundamental na condução de um espaço de discussão, o que confirma a importância de o espaço de discussão ser mediado por um sujeito com escuta clínica afinada com a demanda do coletivo de trabalhadores. É neste espaço de discussão que as regras de trabalho e de convivência podem ser construídas e reconstruídas, é onde o reconhecimento pelo empenho do trabalhador acontece, é o locus no qual as opiniões podem ser formuladas (Rossi, 2008).

A fala dos catadores no coletivo provocou a ação, e isto decorreu do mal estar, do incômodo que a repetição trouxe ao longo das sessões. Essa resistência, por meio das interpretações do coletivo de clínicos levadas a cada sessão, foi sendo elaborada e superada pelos trabalhadores em um processo contínuo de perlaboração. Os catadores reconstruíram significados e começaram a reescrever a história da associação a partir da criação do coletivo gestor. Assim, passaram a entender que a capacidade e o poder de mudança residem no seu coletivo de trabalho, na união das suas forças individuais.

Morrone e Mendes (2003) verificaram em seus estudos com trabalhadores informais da feira dos importados do Distrito Federal uma condição semelhante a dos catadores da ASCAMPA. Observaram que a flexibilidade na organização do trabalho é potencializadora do prazer enquanto a precariedade das condições de trabalho é fonte de sofrimento. Este sofrimento, em ambas as categorias de trabalhadores, foi ressignificado pelo reconhecimento que a atividade informal trouxe aos trabalhadores, pois o trabalho apresenta-se como uma alternativa para a sobrevivência (sua 
e de sua família) diante do desemprego. $\bigcirc$ trabalho de catadores como fonte de sobrevivência foi também pontuado por Sousa e Mendes (2006), sendo que no caso dos catadores cooperativados do Distrito Federal o trabalho não apontou sentido - é destituído de simbolização, de criação e de elaboração, eternizando a condição de alienação e anestesiamento dessa parcela da população excluída historicamente.

Ao longo das sessões, percebeu-se um diferencial entre os catadores da ASCAMPA: organizaram um coletivo gestor, fortalecendo o grupo para enfrentar as fontes geradoras de sofrimento. Diante da pobreza, exclusão e desemprego de longa duração, a oportunidade de trabalho apresenta-se para o sujeito como possibilidade de ser alguém na sociedade, pois é a partir dos ganhos advindos das atividades informais (seja como feirante ou catador) que o trabalhador resgata sua dignidade e consolida sua identidade. Sousa e Mendes (2006) perceberam entre os catadores do Distrito Federal que ter um trabalho é um dos principais fatores de estabilização psíquica e de manutenção da saúde.

Confirma-se, assim, o que Mendes e Araujo (2012) asseveraram sobre a realização de uma clínica com trabalhadores associados: a criação do espaço público de discussão via Clínica Psicodinâmica da Cooperação com os catadores deu visibilidade às tensões dos trabalhadores, antes silenciadas, e deu voz à inteligência prática, para que, cooperativamente, pudessem criar uma gestão participativa, viabilizando a mobilização de um coletivo para encontrar saídas da exclusão histórica vivenciada pelos catadores, resistindo ao modelo de servidão da gestão do trabalho dominante em nossa sociedade. Enfim, "o sofrimento não é patológico, mas um sinal de alerta que, se puder vir à tona, vencer a imobilidade e o medo de se frustrar, obriga o sujeito a sair da acomodação conveniente" (Mendes \& Araujo, 2012, p. 88).

\section{Considerações finais}

A maior demonstração deste estudo é a importância da clínica como potencial político de organização coletiva, pois há problemas em toda organização, seja capitalista ou de produção associada. A diferença está na forma de condução dessas intempéries, sobretudo, falando sobre os incômodos, expondo os sentimentos de mal estar e, principalmente, sugerindo ideias, colocando em ação a inteligência prática cooperativamente, de modo que a mobilização subjetiva do grupo continue a acontecer.

Os limites de práticas clínicas, como esta desenvolvida com os catadores, repousam na disponibilidade do grupo de trabalhadores para expor suas fragilidades em relação ao campo profissional, falarem sobre seu sofrimento com confiança, pois é a partir dessa relação de transferência que pode haver algum tipo de deliberação que promova mudanças na organização do trabalho - a única forma de se buscar saúde e não doença no espaço de trabalho.

Por fim, ao se fazer a escuta do sofrimento dos catadores da ASCAMPA, percebeu-se que houve uma transição de uma gestão individual para uma gestão coletiva, ainda em processo de estruturação e aprendizado, mas aberta a discussões coletivas, com reconhecimento dos desafios. Observou-se o sofrimento no trabalho caminhar na direção da criação, da engenhosidade, se tornando um sofrimento criativo, que atuou como um mobilizador para as mudanças ocorridas na referida associação. Como afirma Moraes (2013, p. 416), esse movimento "beneficia a organização do trabalho e também contribui para a realização pessoal".

Dessa forma, a mobilização subjetiva que aconteceu no percurso da clínica continuou reverberando no coletivo de catadores, e este, após a constituição do coletivo gestor que aos poucos promoveu mudanças na organização do trabalho se apropriando do real do trabalho e da gestão coletiva da ASCAMPA, foi o principal efeito desta prática clínica. 


\section{Referências}

Ascampa (2005). Ata da Assembleia Geral de Fundação da ASCAMPA. Eleição e posse da diretoria. Registrado no Cartório de Registro de Pessoas Jurídicas, Títulos, Documentos e Protestos. Palmas, TO.

Besen, G. R. (2011). Coleta seletiva com inclusão de catadores: construção participativa de indicadores e índices de sustentabilidade. Tese de Doutorado, Faculdade de Saúde Pública, Universidade de São Paulo, São Paulo.

Bortoli, M. A. (2009). Catadores de materiais recicláveis: a construção de novos sujeitos políticos. Rev. Katál. Florianópolis, 12(1), 105-114.

Brasil. (2010). Lei n. 12.305, de 2 de agosto de 2010. Institui a Política Nacional de Resíduos Sólidos; altera a Lei n. 9.605, de 12 de fevereiro de 1998. Legislação Republicana Brasileira. Brasília, 2010. Recuperado em 14 de outubro, 2011, de http://www.planalto.gov.br/ccivil_03/_ato2007-2010/2010/lei/112305.htm.

Carvalho, A. M. R. (2008). Cooperativa de catadores de materiais recicláveis de Assis - COOCASSIS: espaço de trabalho e de sociabilidade e seus desdobramentos na consciência. Tese de Doutorado. Universidade de São Paulo, São Paulo.

Dejours, C. (2004). Sofrimento e prazer no trabalho: a abordagem pela psicopatologia do trabalho. In Lancman, S. \& Sznelwar, L. (Orgs.) Christophe Dejours: da psicopatologia à Psicodinâmica do Trabalho. (3a ed. rev., S. Lancman \& L. Sznelwar, trads.; pp. 141-156). Rio de Janeiro: Fiocruz Brasília: Paralelo 15.

Dejours, C. (2011). Addendum da psicopatologia à Psicodinâmica do Trabalho. In S. Lancman \& L. Sznelwar (Orgs.) Christophe Dejours: da psicopatologia à Psicodinâmica do Trabalho. (3a ed. rev., S. Lancman \& L. Sznelwar, trads, pp. 57-123). Rio de Janeiro: Fiocruz; Brasília: Paralelo 15.

Dejours, C. (2012). Trabalho vivo: trabalho e emancipação (tomo 2, Soudant, F., trad.). Brasília: paralelo 15. 222 p.

Feitosa, L. de B. (2011). Sentidos atribuídos às políticas públicas de inclusão dos catadores pelos atores envolvidos nas discussões dos resíduos sólidos. Dissertação de Mestrado, Universidade Federal do Ceará, Fortaleza.

Ferreira, A. S. da (2013). A Psicodinâmica do Trabalho de Profissionais de Odontologia do Centro Ambulatorial de um Hospital Universitário. Dissertação de Mestrado, Universidade de Brasília, Brasília.

Ferreira, J. B. (2007). Trabalho, sofrimento e patologias sociais: estudo com trabalhadores bancários e anistiados políticos de uma empresa pública. Dissertação de Mestrado Universidade de Brasília, Brasília.

Ferreira, J. B., Mendes, A. M., Lima, S. C da C., Facas, E. P. \& Ghizoni, L. D. (2013). Entre a mobilização subjetiva e a subtração do desejo: estudos com base na psicodinâmica do trabalho. In A. R. C. Merlo, A. M. Mendes \& R. D. Moraes (Orgs.). O sujeito no trabalho: entre a saúde e a patologia. (Biblioteca Juruá de Psicodinâmica e Clínica do Trabalho, pp. 101-118). Curitiba: Juruá.

Freitas, L. F, da S. \& Fonseca, I. F. (2012). Diagnóstico sobre catadores de resíduos sólidos. Brasília: IPEA.

Ghizoni, L. D. (2013). Clínica Psicodinâmica da Cooperação na Associação de Catadores e Catadoras de Materiais Recicláveis da Região Centro Norte de Palmas - TO (ASCAMPA). Tese de Doutorado, Instituto de Psicologia, Universidade de Brasília, Brasília.

Ghizoni, L. D. \& Cançado, A. C. (2011). Relatório final do projeto: "coleta seletiva: conexões para uma vida sustentável”.

In L. D. Ghizoni \& A. C. Cançado (Orgs.) Desenvolvimento, gestão e questão social: uma abordagem interdisciplinar (pp. 19-36). Contagem, MG: Didática.

Ghizoni, L. D. \& Mendes, A. M. (2014). Dispositivos para uma escuta clínica do sofrimento no trabalho dos catadores de materiais recicláveis. Contextos Clínicos, 7(1),15-26.

Ghizoni, L. D., Mendes, A. M. \& Corgozinho, J. P. (2013). Uma proposta brasileira para a Clínica Psicodinâmica do Trabalho. In V. L. D. C. Schlindwein (Org.). Saúde mental e trabalho na Amazônia: múltiplas leituras sobre prazer e sofrimento no trabalho. Porto Velho, RO: EDUFRO.

Gomes, M. L. B. M, Lima, S. S. C. \& Mendes, A. M. (2011). Experiência em clínica do trabalho com profissionais de T\&D de uma organização pública. Estudos e Pesquisas em Psicologia, 11 (3), 841-855.

Gonçalves, P. (2003). A reciclagem integradora dos aspectos ambientais, sociais e econômicos. Rio de Janeiro: DP\&A: Fase. Lima, S. C. da C. (2011). Coletivo de trabalho e reconhecimento: uma análise psicodinâmica dos cuidadores sociais. Tese de Doutorado, Universidade de Brasília, Brasília. 
Lhuilier, D. (2011). Filiações teóricas das clínicas do trabalho. In P. F. Bendassoli \& L. A. Soboll (Orgs). Clínicas do trabalho. (pp. 22-58) São Paulo: Atlas.

Medeiros, S. N. (2012). Clínica em Psicodinâmica do Trabalho com a Unidade de Operações Aéreas do DETRAN: o Prazer de Voar e a Arte de se Manter Vivo. Dissertação de Mestrado, Universidade de Brasília, Brasília.

Medeiros, L. F. R. \& Macêdo, K. B. (2006). Catador de material reciclável: uma profissão para além da sobrevivência? Psicologia E⿱ Sociedade, 18(2), 62-71.

Mendes, A. M. (2007). Da psicodinâmica à psicopatologia do trabalho. In A. M. Mendes (Org.) Psicodinâmica do Trabalho: teoria, método e pesquisas. (pp. 29-48) São Paulo: Casa do Psicólogo.

Mendes, A. M. (2008). Prazer, reconhecimento e transformação do sofrimento no trabalho. In A. M. Mendes (Org.). Trabalho Ė Saúde: o sujeito entre emancipação e servidão. (pp. 13-25). Curitiba: Juruá.

Mendes, A. M., Alves, J. J. \& França, A. M. L. D. (2011). Análise da psicodinâmica do trabalho de taquígrafos parlamentares brasileiros. Revista Pessoas Ë Sintomas, Braga, Portugal, 15, 8-17.

Mendes, A. M \& Araújo, L. K. R. (2012). Clínica Psicodinâmica do Trabalho: o sujeito em ação. Curitiba, Juruá.

Mendes, A. M. \& Muller T. da C. (2013). Prazer no trabalho. In F. O. Vieira, A. M. Mendes \& A. R. C. Merlo (Orgs.). Dicionário crítico de gestão e psicodinâmica do trabalho. (pp. 289-292). Curitiba: Juruá.

Merlo, A. R. C., Dornelles, R. A. N., Bottega, C. G. \& Trentini, L. (2012). O trabalho e a saúde dos oficiais de Justiça Federal de Porto Alegre. Cadernos de Psicologia Social do Trabalho, 15(1), 101-113.

Moraes, R. D. (2013). Sofrimento criativo e patogênico. In F. O. Vieira, A. M. Mendes \& A. R. C. Merlo (Orgs.). Dicionário crítico de gestão e psicodinâmica do trabalho. (pp. 415-419). Curitiba: Juruá.

Morrone, C. F. \& Mendes, A. M. (2003). A ressignificação do sofrimento psíquico no trabalho informal. rPOT, 3(2), 91-118.

Rossi, E. Z. (2008). Reabilitação e reinserção no trabalho de bancários portadores de LER/DORT: análise psicodinâmica. Tese de Doutorado, Universidade de Brasília, Brasília

Santos, G. O \& Silva, L. F. F. (2009). Há dignidade no trabalho com o lixo? Considerações sobre o olhar do trabalhador. Revista Mal-estar e Subjetividade, IX(2), 689-716.

Santos-Junior, A. V., Mendes, A. M. \& Araujo, L. K. R. (2009). Experiência em clínica do trabalho com bancários adoecidos por LER/Dort. Revista Psicologia Ciência e Profissão, 29(3), 614-625.

Silva, M. C. dos S. Q. \& Mendes, A. M. (2012). Prática em clínica psicodinâmica do trabalho como estratégia de promoção da saúde. Tempus - Actas de Saúde Coletiva, 6(2), 195-207.

Sousa, C. M. de \& Mendes, A. M. (2006). Viver do lixo ou no lixo? A relação entre saúde e trabalho na ocupação de catadores de material reciclável cooperativos no Distrito Federal: Estudo exploratório. rPOT, 6(2), 13-42.

Tiriba, L. (2007). Educação popular e pedagogia(s) da produção associada. Cad. Cedes, 27(71), 85-98.

Tiriba, L. \& Fischer M. C. B. (s.d.). Produção associada e autogestão. [s.l.: s.n.].

\section{Endereço para correspondência}

ldghizoni@gmail.com, anamag@unb.br
Recebido em: 21/03/2014

Revisado em: 10/09/2014

Aprovado em: 06/10/2014 